\title{
APPLICATIONS OF ADDITIVE TECHNOLOGIES IN REALIZATION OF CUSTOMIZED DENTAL PROSTHESESR
}

\author{
Edgar Moraru ${ }^{1}$,Daniel Besnea ${ }^{2}$, Octavian Dontu ${ }^{3}$, Gheorghe I. Gheorghe ${ }^{4}$, Victor Constantin ${ }^{5}$ \\ 1,2,3,5 Politehnica University of Bucharest, Splaiul Independenţei no. 313, 6th District, Bucharest \\ ${ }^{4}$ INCDMTM, Pantelimon Road, No. 6-8, 2nd District, Bucharest

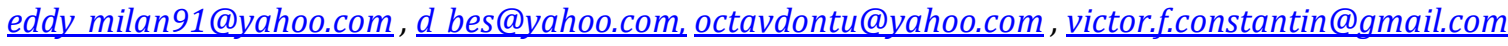 \\ geocefin@yahoo.com
}

\begin{abstract}
The paper presents 3D DLP (Digital Light Processing) digital printing technology, which belongs to the additive technology category using liquid raw material allowing the obtaining of dental prostheses with complex and detailed geometry, fine and precise printed surfaces, fairly resistant dental crowns, with a variety of resins, including biomedical materials (certified for medical use), characterized by high print speed and productivity for complex geometries and high productivity with numerous applications in the medical field. In the paper, a prototype of a dental bridge was made using 3D DLP printing technology, which can serve as a model for future dental restorations.
\end{abstract}

Keywords: 3D printing, Photopolymerization, Digital Light Processing, Dental Prostheses, Additive Manufacturing.

\section{Introduction}

Three-dimensional printing is a modern technology with applications in several domains. The flexibility of the 3D printing system allows the use of a variety of materials. Most Additive Manufacturing systems using liquid raw materials use a heat source that scans the 2D surface of the liquid, and at impact with it, produces "point-to-point" or "surface-to-surface" solidification. The piece is built on a horizontal platform submerged in the liquid polymer. The solidification is achieved by the photopolymerization produced at the impact of a light ray with the upper surface of the liquid. Photopolymers are lightsensitive polymeric materials that change their physical or chemical properties when exposed to an external stimulus (heat source, ultraviolet radiation, etc.). The main source of light is UV light, which initiates a reaction and changes the properties of photopolymers.

The photopolymer has special properties in the sense that radiation in the ultraviolet or visible field initiates the polymerization at a depth of several tenths of a millimeter below the surface of the liquid is restricted to a shape corresponding to a cross section of the piece. After solidifying a layer the piece is submerged with a new section thickness and a new cross section of the piece is solidified. The entire cycle is repeated until the piece is solidified in its totality [1].

The commonly used photopolymer, the ester of cinnamic acid (C9H802)) is produced by reacting cinnamic acid with alcohol in the presence of light [2]. After the piece has been obtained by this process, a post-processing operation is carried out using a light and / or heat source that must be so chosen that it does not destroy or distort the piece (laser, UV, sunlight, etc.). Light from these sources initiates chemical reactions that change their structure and change their chemical and mechanical properties. The fact that photopolymerisation occurs only a few tenths of a millimeter thick on the surface of the liquid allows the use of less translucent polymers and lower light intensity. Some of the common polymeric bases are polyvinyl cinnamate, polyamide (PA), polyisoprene, polyimides, epoxides, acrylics etc. Usually with these polymers, monomers, oligomers and additives are used [3].

Binders are reactive intermediate molecular weight molecules consisting of several monomer units, usually dimers (two units), trimers (three units) and tetramers (four units). They are normally liquid at room temperature and are used as ink, adhesives and coatings. Typical photopolymers consist of $50-80 \%$ of such binders / oligomers, some examples of binders:

- Styrene family: Oligomer Of Styrene-TetramerAlpha Cumyl End Group, A-Methyl

Styrene-Dimer (1), A-Methyl Styrene-Tetramer etc

- Methacrylate family: Acrylic Acid Oligomers, Methyl Methacrylate Oligomers, Methyl

Methacrylate Tetramer etc

- Vinylalcohol family: Vinyl Alcohol Trimer, Vinylacetate Trimer, Vinylacetate Oligomer 
- $\quad$ Olefine family: Poly Isobutylene

- Glycerol family: Triglycerol

- Polypropylene Glycol Family: Poly Propylene Glycol (Dihydroxy Terminated) etc.

Monomers are small chemically bound molecules that repeatedly bind to other monomers, oligomers or polymers to form new polymers. Mostly photopolymers consist of monomers based on acrylates or methacrylates ranging from 10 to $40 \%$. In the polymerization process, two types of monomers can be used: multifunctional monomers and monofunctional monomers. Multifunctional monomers can act as both diluents and cross linkers, while monofunctional monomers may be either diluents or crosslinkers.

Table1. Monofunctional and multifunctional monomers

\begin{tabular}{|l|l|}
\hline $\begin{array}{l}\text { Monofunctional } \\
\text { monomers }\end{array}$ & Multifunctional monomers \\
\hline Acrylic acid & $\begin{array}{l}\text { Trimethyllopropanetriacrilate } \\
\text { (TMPTA) }\end{array}$ \\
\hline Methacrylic acid & Ethoxylated TMPTA \\
\hline Isodecylacrylat & $\begin{array}{l}\text { Trymethyllepropanetrimetha } \\
\text { crylate }\end{array}$ \\
\hline $\begin{array}{l}\text { N-vinyl } \\
\text { pyrrolidone }\end{array}$ & Hexanedioldiacrylate \\
\hline
\end{tabular}

The photoinitiators convert light energy into chemical energy by forming free radicals or cations upon UV exposure. They can break into two or more particles with UV reaction and at least one of the particles will react with monomers or oligomers and binds them together. They exist naturally or can be chemically synthesized and are sensitive to specific wavelengths of light. The photo-initiators form only a small component of photopolymers [2].

Table 2. Examples of photoinitiators

\begin{tabular}{|l|l|}
\hline $\begin{array}{l}\text { Free radical } \\
\text { photoinitiators }\end{array}$ & $\begin{array}{l}\text { Cationic } \\
\text { photoinitiators }\end{array}$ \\
\hline Isopropylthioxanthone & $\begin{array}{l}\text { Diaryliodonium } \\
\text { salts }\end{array}$ \\
\hline Benzophenone & $\begin{array}{l}\text { Triarylsulfonium } \\
\text { salts }\end{array}$ \\
\hline
\end{tabular}

In the photo-polimerization of free radicals, the radicals or ions break off the initiators when UV reacts and the ions will begin to react with monomers to initiate the polymerization. During the cationic reaction, the strong acid will be released from the initiator and a binding process begins.
Diaryliodonium and Triarylsulfonium salts are stable crystalline compounds which can be prepared by synthetic method and are available in the market for commercial purpose [2].

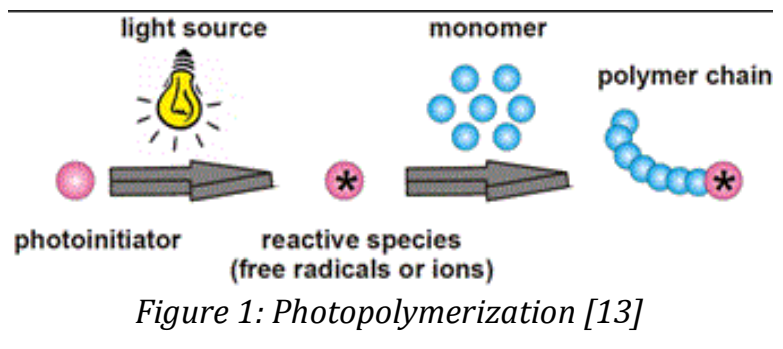

Our teeth play a very important role in our daily lives. They help not only to crush the food, but also to improve the digestive process. Moreover, they are aesthetically important. We can conclude that the teeth should be in a complete set. Only in these circumstances a person will be able to maintain his health and attractiveness [4]. Modern dentistry has taken the best ideas since antiquity and has multiplied it into today's technologies and materials. As a result of this symbology, the dental prostheses of today's days have appeared, which are worthy of admiration. They are dental structures designed to restore the anatomy and physiology of the dentition. Most often, the prostheses should be installed if one or more teeth have been lost.

A person may lose teeth because of various diseases (such as dental caries and periodontitis). In addition, the cause of the loss may be the lesion or malformation of the dental system. The installation of dental prostheses allows restoration of mastication, speech, avoidance of teeth movement. Almost all modern prostheses are very close to the properties and aspect of the natural teeth.

The actual manufactured prostheses are comfortable, practical and with proper care they can serve for a long time [6].

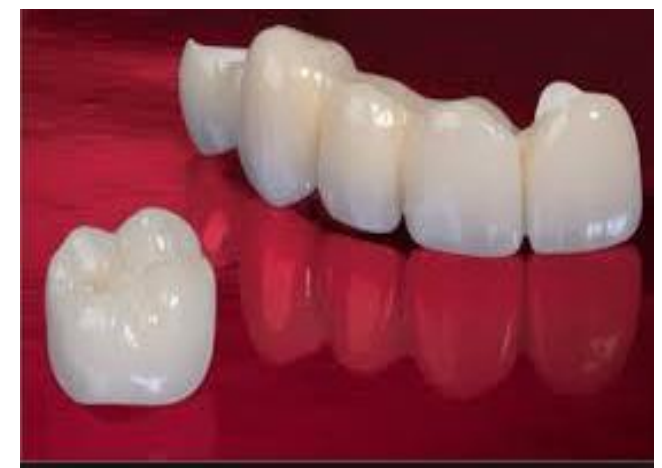

Figure 2: Ceramic dental crown [7]

Dental prostheses can be classified from several points of view: by mobility (removable, mobile, and fixed), depending on the aesthetic aspect (physiognomic, semi-physiognomic, nonphysiognomic), depending on the material used (metallic, ceramic, metal-polymeric, metal-ceramic, etc.). 
This branch of prosthetic dentistry is constantly developing. More and more often we hear from different sources about the possibilities of a new 3D printing technology [14]. After all, if it is possible to print any three-dimensional figure, why would not it be possible to print a tooth? Compared to milling, everything is exactly the opposite, we do not eliminate too much, but the layer with layer is formed or "imprinted" the future prosthesis according to the $3 \mathrm{D}$ CAD / CAE model. The fabrication of prostheses using CAD technologies allows providing support for each irregularity of the later metal-ceramic restoration, since it first models the anatomical shape and then using the programs, uniformly removing the ceramic application layers.

This ensures the stability of the restoration and a long lifetime of the construction [15].

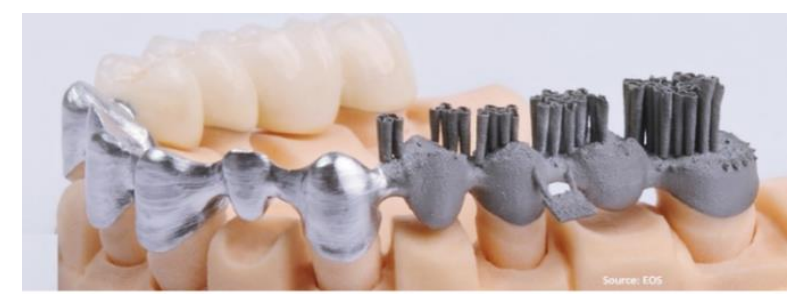

Figure 3: Proteza dentara realizata prin tehnica aditiva (SLS - Sinterizare Selectiva cu Laser) [16]

An application of great impact and perspective has AM(Additive Manufacturing) technologies in the field of personalized medical implantology. The development of these applications has gone from two premises: the first is that every human is a prototype, and the second, the ability of computed tomography (CT) or nuclear magnetic resonance (PMN) systems to deliver data and information to go end to a virtual 3D model of the area of interest that can be saved as a .stl file, specific to the fabrication technology by adding material. From this moment on, the physical materialization of the virtual model of interest in a process of implantology or bone reconstruction is treated like any other piece. A physical model in this field can have several utilities:

- He can serve in the proper diagnosis and selection of suitable therapy, improving communication between different groups of doctors;

- The three-dimensional physical model can be used in the planning of very complex surgical interventions that can be "practiced" on these models. For example, in maxillofacial surgery for osteotomy planning, for correct choice of bone sectioning paths and how to rearticulate them;

- Using a physical model makes it easier and more precise to realize a prosthesis or implant;

- It can even be a personalized implant made of biocompatible material for the patient;

Applications of AM technologies in this area are gaining more and more importance. Challenges are related to the finding and approval of new biocompatible materials that can be put into the desired physical form, with physico-mechanical structures and properties as close as possible to those of the bone part it replaces [1].

\section{Materials and Methods}

DLP Printing Technology (Digital Light Processing) is an additive manufacturing process based on the use of UV light for the solidification of liquid polymer resins. DLP technology has as its main element the DMD (Digital Micromirror Device) chip - a matrix of micro-mirrors used for fast spatial light modulation. Each individual micro-mirror of the DMD chip projects pixels from the cross-section of the 3D model. Under the action of UV light, the photo reactive liquid (sensitive to ultraviolet light) solidifies in successive layers. Because the entire cross section is projected into a single exposure, the construction speed of a layer is constant regardless of the complexity of the geometry. 3D objects of more complex geometries are printed with support materials that are later removed. The resin remaining in the construction vat can be reused for later printing. For some printed materials, subsequent curing processes in UV furnaces may be required. Table 3 lists some of the features of Digital Ligth Processing technology.

Table 3 Features of DLP technology

\begin{tabular}{|l|l|}
\hline $\begin{array}{l}\text { Accuracy of } \\
\text { printed parts }\end{array}$ & Very good \\
\hline $\begin{array}{l}\text { Finishing } \\
\text { printed surfaces }\end{array}$ & Very good \\
\hline Print speed & $\begin{array}{l}\text { Good(for multiple objects } \\
\text { and complex geometries) }\end{array}$ \\
\hline Used materials & $\begin{array}{l}\text { resins, photopolymers, } \\
\text { transparent resins }\end{array}$ \\
\hline
\end{tabular}

Advantages of DLP (Digital Light Processing) technology: Fine and precise printed surfaces (use in the jewelry industry, dental technology, electronics), the prototypes is quite resistant for processing, a variety of resins including bio-medical materials (certified for medical use) and transparent resins (prototypes in the packaging industry), stable printers with few moving parts. The technology allows prototyping of parts with complex and detailed geometries, high printing speed for complex constructions and simultaneous printing of many pieces (high productivity). Printed parts can be used as master molds for injection molding, thermoforming, metal casting.

Disadvantages of DLP (Digital Light Processing) technology: Expensive building materials, higher 3D printer prices (for large volumes), require postprocessing operations (UV curing, removal of support material) require handling of resins.

DLP (Digital Light Processing) technology applications: Resistant prototypes for functional 
testing, fine prototypes and models, precise prototypes with complex geometries; fabrication of small series of models in medicine (dental models, dental implants, cochlear implants, dental restorations, medical implants), media models (animation, cinema), jewellery casting models, tools and instruments, parts and components in automotive and aerospace industry [8-12].

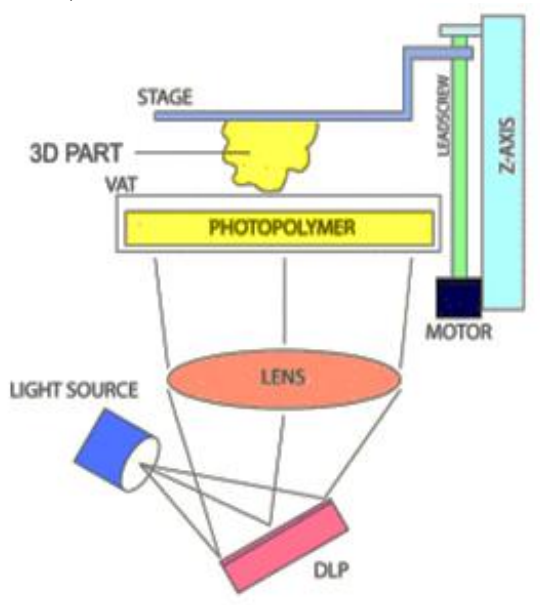

Figure 4: DLP Digital Light Processing printing technology

\section{Experimental}

The experimental research consists of creating a dental prosthesis with a 3D Duplicator 7 printer that uses the direct impact of photosensitive resin with UV light transmit-ted through an LCD screen, Fig. 5.

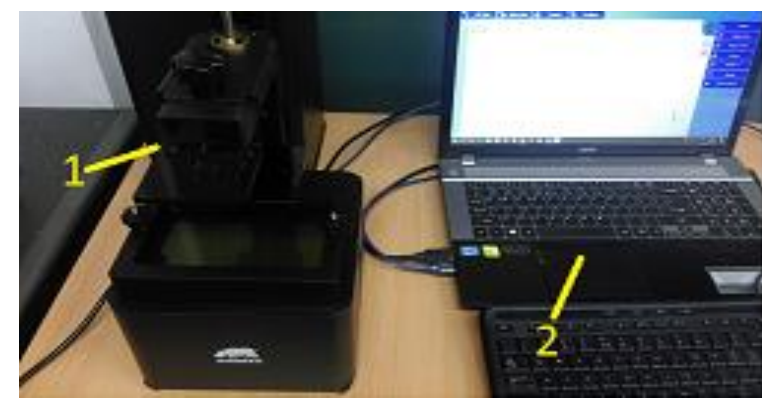

Figure 5: .3D Duplicator Printer 7, general view; 1 - 3D Duplicator; 2 - PC
It starts from a CAD model that is saved in .stl format and can be processed by the 3D Duplicator 7 software (Fig.6).

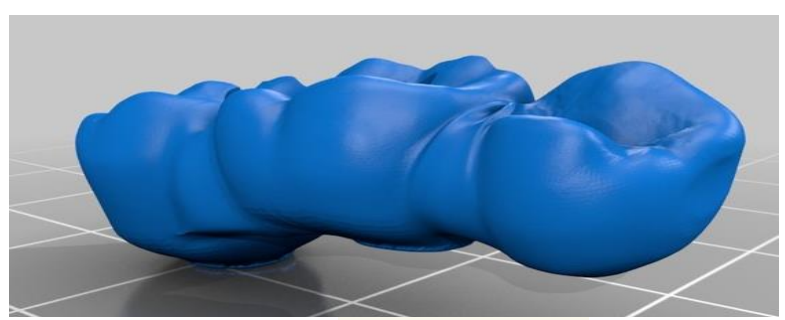

Figure 6: Dental prosthesis

The Creation Workshop software allows the visualization and position of the work-piece on the work plane as well as the mirroring operations. The interface is shown in Fig. 7.

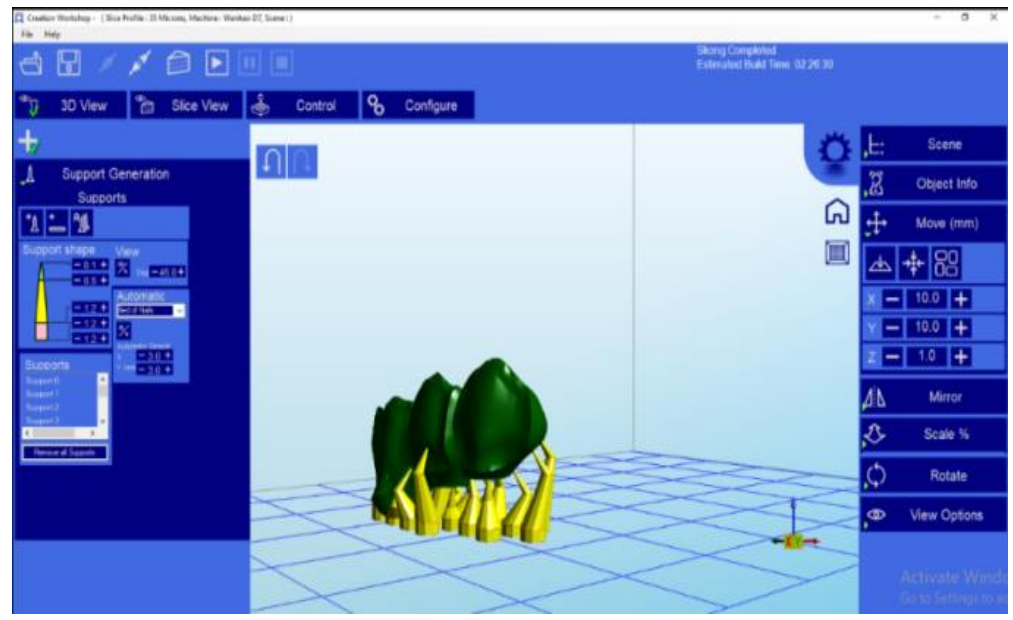

Figure 7: Program interface 
Dental prosthesis from the CAD model does not have a laying surface, in this case it is necessary to add a sacrificial layer, as shown in the figure above.
The technical specifications of the 3D Duplicator 7 printer are shown in Table 4:

\begin{tabular}{|c|c|c|c|}
\hline \multicolumn{2}{|c|}{$\begin{array}{c}\text { Technical specifications of the 3D } \\
\text { Duplicator Printer7 }\end{array}$} & \multicolumn{2}{|c|}{ Resin specifications } \\
\hline Print volume & 2,11 & Wavelength & $405 \mathrm{~nm}$ \\
\hline Print sizes & $120 \times 68 \times 200 \mathrm{~mm}$ & Solidification time & $8-16 s$ \\
\hline Thickness layer & $\min .0,035 \mathrm{~mm}$ & Viscosity (at $25^{\circ} \mathrm{C}$ ) & $120-140 \mathrm{mPa}^{*} \mathrm{~s}$ \\
\hline Print speed & $30 \mathrm{~mm} / \mathrm{h}$ & Density (at $25^{\circ} \mathrm{C}$ ) & $1,12 \mathrm{~g} / \mathrm{cm}^{3}$ \\
\hline Rezolution XY & $2560 x 1440 \mathrm{px}$ & Hardness (XY) & $79,2 \mathrm{MPa}$ \\
\hline Software & Creation Workshop & Hardness $(\mathrm{Z})$ & $73,5 \mathrm{MPa}$ \\
\hline & & Flexural strength $(\mathrm{XY})$ & $8,43 \mathrm{MPa}$ \\
\hline & & Flexural strength (Z) & $5,57 \mathrm{MPa}$ \\
\hline & & Tensile strength (XY) & $21,4 \mathrm{MPa}$ \\
\hline & & Tensile strength (Z) & $15,2 \mathrm{MPa}$ \\
\hline
\end{tabular}

While FDM technology produces a mechanical bond between layers, DLP (Digital Ligth Processing) technology creates a chemical bond by bonding the photopolymers through layers, resulting in very dense parts, the bond is water and air tight, and the resistance does not changes according to orientation.

The experimental results led to the realization of a prototype of the dental prosthesis which is shown in fig. 10 .

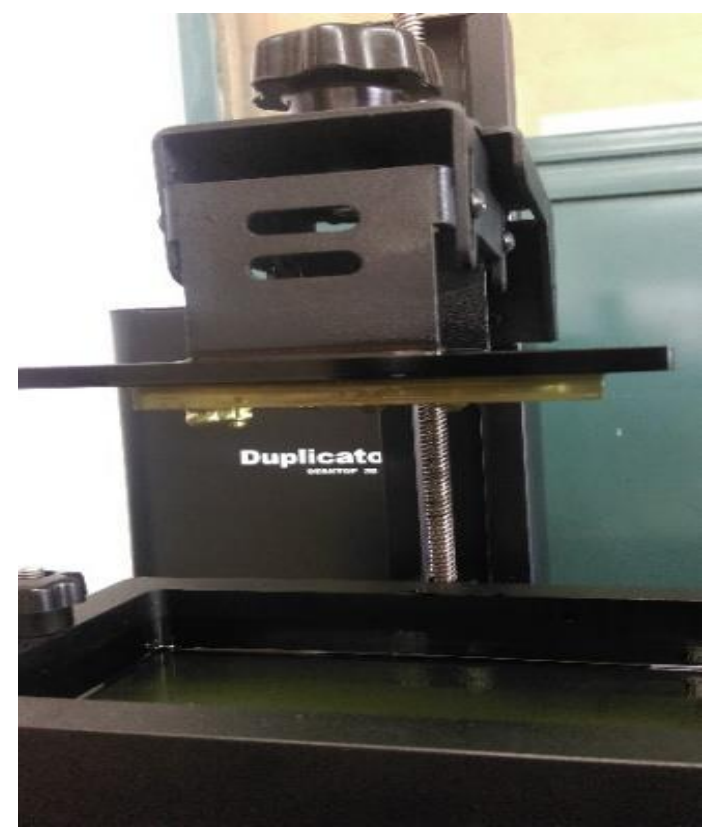

Figure 8: 3D Duplicator Printer 7[8]
In about two and a half hours a prototype of dental prosthesis has been obtained that can be a landmark for the dentist in order to obtain the future prosthetic restoration.

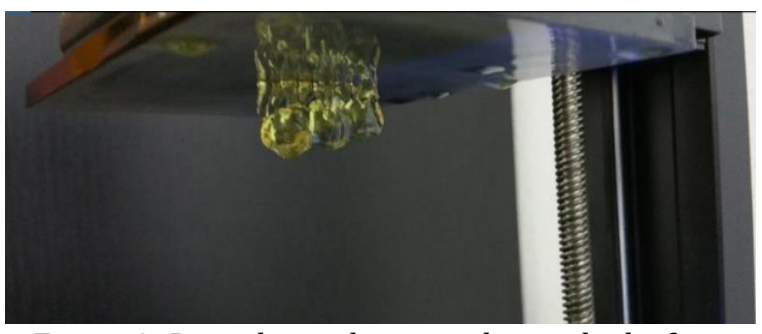

Figure 9: Dental prosthesis on the work platform

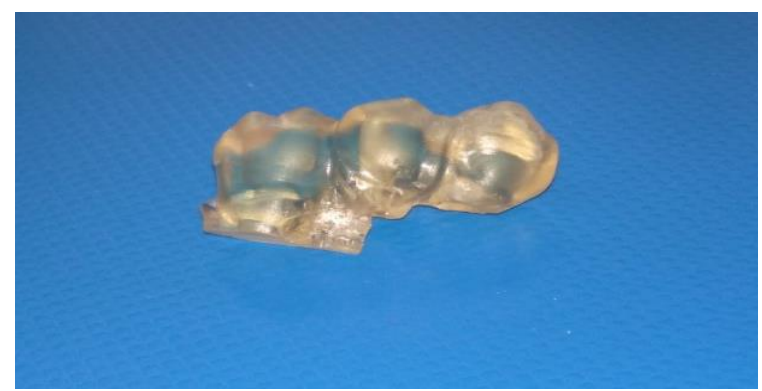

Figure 10: Dental prosthesis obtained with DLP Digital Light Processing technology

The sacrificial layer was later removed, the prosthesis being cleaned in a $92 \%$ technical alcohol bath. After this, the restoration was left for 24 hours in a water recipient to complete the photo polymerization. 


\section{Conclusions}

The development of photopolymers with desired properties such as chemical composition, mechanical, high degree of biocompatibility will be useful in the creation of complex products and thus increase the application areas, especially in the medical field.

Tooth loss due to various pathologies at present is considered to be a serious health problem. In this case, not only the aesthetic and phonetic roles intervene. Perhaps the most important function of the teeth is mastication, thus improving the digestive process by shredding the food. Because of this the installation of dental prostheses that replace the lost or damaged teeth is absolutely indispensable.

Throughout the existence of dentistry science, it has appeared a wide range of procedures and techniques for replacing dental defects. They are constantly improved along with the evolution of the scientific base, and at the same time new methods, materials and technologies are found to minimize or eliminate the inherent shortcomings of a treatment method. Lately, the additive technologies have gained much ground regarding the realization of dental prostheses, gradually replacing convention-al casting technologies. These technologies provide an efficient and rapid method for designing and manufacturing biocompatible metal, ceramic and polymeric carcasses for complex dental frameworks. The selective laser sintering is one of the additive technologies that result in dental crowns with high performance features. The unused material can be used in the following processes, making this technology more efficient from economical point of view than CAD milling, the other completely opposite technology for creating prostheses.

In the coming years, notable achievements will be highlighted in this field, both in terms of new biocompatible materials and the ability of AM Additive Manufacturing technologies to achieve dental prostheses with variable structures.

This study highlighted the realization of prototypes of dental prostheses using Digital Ligth Processing technology, yielding admirable results that can be used as models for future customized dental crowns or even as temporary prostheses.

\section{Acknowledgements}

This work has been funded by University POLITEHNICA of Bucharest, through the "Excellence Research Grants", Program UPB-GEX 2017. Identify:
UPB-GEX2017, Grant no. 48/25.09.2017, ME 14-1705, ID98.

\section{References}

[1] Petru Berce, Nicolae Balc, Cristian Caizar, Razvan Pacurar, Adrian Sever Radu, Sorin Bratean, Ioan Fodorean, Tehnologii de fabricatie prin adaugare de material si aplicatiile lor, Editura Academiei Romane, Bucuresti, 2014.

[2] Ramji Pandey, Photopolymers in 3D printing applications, Degree Thesis Plastics Technology, 2014

[3] John T. Sheridan, Photopolymers Materials (Light Sensitive Organic Materials): Characterization and Application to 3D Optical Fabrication and Data Storage, 2014

[4] http://worlddent.ru/zubnye-protezy

[5] http://www.rusmedserv.com/toothreplacement /denture/

[6] http://www.lacalut.ru/information/articles/vie w/185-fixation-prostheses

[7] https://www.mycostamesadentist.com/blog/cho osing-your-dental-crown/

[8] www.wanhao3Dprinter.com

[9] 3D Printing with Desktop Stereolithographz, An Introduction for Profesional Users, June 2015, formlabs.com

[10] Yuanyuan Xu, Xiaoyue $\mathrm{Wu}$, Xiao Guo, Bin Kong , Min Zhang, Xiang Qian, ShengliMi, and Wei Sun, The Boom in 3D-Printed Sensor Technology, Sensors 2017, 17, 1166; doi:10.3390/s17051166

[11] Bethany C. Gross, Jayda L. Erkal, Sarah Y. Lockwood, Chengpeng Chen, and Dana M. Spence, Evaluation of 3D Printing and Its Potential Impact on Biotechnology and the Chemical Sciences, XXXX American Chemical Society, dx.doi.org/10.1021/ac403397r

[12] 3D Printing with Desktop Stereolithography, An Introduction for Professional Users, June 2015, formlabs.com

[13] http://web.itu.edu.tr/ yusuf/index-1.htm

[14] http://www.print3dbucuresti.ro/aplicatiiprintare-3D/printare-3d-tehnica-dentara/

[15] А.А. Майстренко, Л.Г. Толчек Компьютерные технологии в стоматологии

[16] https://www.sinterex.com/metal-3dprinting-and-additivemanufacturingblog/2016/6/13/see-howdentistry-is-benefiting-from-metal-3D-printing. 